\title{
Comprehensive Literature Review of Perinatal Loss Supports
}

\author{
Stephanie Brown* \\ Visiting Assistant Professor, Department of Nursing, St. John Fisher College, USA
}

*Corresponding author: Stephanie Brown, Visiting Assistant Professor, Department of Nursing, St. John Fisher College, USA.

Received Date: June 12, 2019

Published Date: June 28, 2019

\begin{abstract}
Introduction: Miscarriage, stillbirth or newborn death is a significant and under recognized issue in the United States.

Methods: Comprehensive review of literature to evaluate the feasibility of support for perinatal community.

Results: Literature is inconclusive if perinatal loss support groups may be helpful for families experiencing a loss; however, further exploration is needed. in participants of a perinatal loss peer support group.

Conclusion: Results suggest that integrating professionally facilitated grief work classes in perinatal loss support group members were beneficial.
\end{abstract}

Keywords: Perinatal loss; Peer support; Social support; Dual process mode

\section{Introduction}

More than one million families in the United States experience miscarriage, stillbirth or newborn death every year [1]. Stillbirth refers to fetal death in utero, which accounts for two percent of pregnancies [2]. About 12-31 percent of all conceptions end spontaneously due to early or late fetal death [3].

Pregnancy loss is associated with increased stress levels, which can progress to physical and mental health consequences, including depression, anxiety, obsessive-compulsive disorder, suicide, marital conflict, post-traumatic stress disorder, and fatigue [3]. These consequences can persist for months or years post loss [3].

Social or peer support has been linked to improved health outcomes and prevention of disease [3]. Perinatal loss support groups have been found to help participants cope with psychiatric disturbances, improve marital quality, and improve coping strategies [4].

\section{Background}

Little is known regarding the potential impacts of peer support in the setting of perinatal loss. Given this challenge a comprehensive literature review was conducted surrounding perinatal loss. Electronic databases (Cochrane Database of Systematic Reviews,
CINAHL, Medline, PsycINFO and PubMed) were searched using key terms (perinatal loss, miscarriage, stillbirth, fetal death, coping, dual process model, satisfaction, knowledge, quality of life, and support), and relevant public policies, internet sources, and local area newspapers were reviewed. In total, 134 sources were synthesized to inform the background and methods of this work. Concepts inherent in the examined literature regarding perinatal loss experience, grief, coping, knowledge acquisition, and support will be explored in more detail as well as the guiding theoretical framework.

\section{Literature Review}

\section{Experience of perinatal loss}

The effects of perinatal loss, defined as miscarriage, stillbirth or newborn death, can be significant, especially for mothers. Mothers often express feelings of depression and can become withdrawn after a loss [5]. These mothers commonly fear the unknown and have premonitions of dying early [6]. Feelings of self-blame and guilt also have been reported [7]. Mothers often describe experiencing a loss of self, lack of memories surrounding the baby, loss of future hope, and minimization of the loss by others [3]. 
The process of dealing with perinatal loss is specific to the individual, may last months or years, and can extend into subsequent pregnancies. Mothers experiencing loss can also face a variety of mental health obstacles including: anxiety, depression, obsessive-compulsive disorder, suicide, marital conflict, and posttraumatic stress disorder [3].

\section{The impact of grief and coping}

Grief is a complex process and can often include significant feelings of guilt [8]. After a perinatal loss, both men and woman are susceptible to a resurgence of grief even years after the loss. The grief process can be further complicated if parents do not find their own time to grieve [5]. Coping can be defined as an "action oriented and intrapsychic effort used to manage the demands created by stressful events" Amoyal NR, et al. [9] and requires the recognition of the impact of stress specifically related to mental and physical health outcomes [9]. Supporting coping related to a perinatal loss was a focus of this pilot. Investigating the dynamics of grief and coping over time could serve as a valuable intervention in the setting of perinatal loss.

\section{Knowledge acquisition}

Scant literature is present examining the role of knowledge in affecting the process of grief, especially when examining health outcomes. Experiencing a loss can lead to a decrease in energy and self-worth, which then contributes to the complexity of the grieving process [10]. Hibbard JH and Greene J [11], however, determined that patients who took an active role in their own health, secondary to increased knowledge, had better health outcomes and care experiences. noted improvements in patient knowledge base with interventions designed to promote self-care, improve self-efficacy, increase patient satisfaction, enhance coping skills, and improve perceptions of social support $[12,13]$.

Adams RJ [12] also states that increased knowledge assessment tools are needed. A comprehensive literature review was conducted to search for knowledge assessment tools. However, no validated tool relating to perinatal loss was discovered that would be applicable for a pilot study. Therefore, a qualitative knowledge acquisition survey tool was created to further assess this need for the purpose of this pilot.

\section{Support groups}

Both self-help groups and support groups function with the goal of helping others. About 25 million Americans have attended self-help/support groups during their lifetime and of these, 10 million have attended a group within the last year [14].

Specific to perinatal loss, support groups have been noted to be effective in reducing the distress of parents and improving parents' overall mental health, relationship quality, and parental coping strategies [4]. Common themes identified by support group members included dealing with anniversaries, jealousy of pregnant friends, denied feelings, communication problems, marriage difficulties, guilt, future pregnancies and concerns regarding current children. Participants reported validation of feelings, acknowledgment of experiences, and decreased guilt as a result of support group membership. Perinatal loss support groups were also noted to help restore hope for the future and to increase communication within relationships among participants [15]. This background the planning if this pilot study.

Hoey LM, et al. [16] concluded that peer support programs can improve satisfaction with medical care, improve personal relationships and social support, increase a sense of belonging, and enhance mood. Schopler JH, Galinsky MJ [17], noted similar themes. Group social or peer support provided participants with a sense of relief, reassurance, enhanced coping skills, greater self-confidence, decreased fear, decreased ambiguity, a sense of being cared for, a feeling of purpose, emotional release, reduced helplessness, and a greater ability to meet demands [17].

\section{Theoretical framework}

The Dual Process Model (DPM) of bereavement coping was developed in 1999 by [18-20]. The DPM consists of two phases: loss-oriented coping and restoration orientation coping. Loss orientation pertains to the aspects of the death itself. It involves confronting feelings of grief while confiding in [21]. In this model, the bereaved individual is appraising and concentrating on the primary aspect of the loss itself. This is referred to as doing the "grief work" [22]. Restoration oriented coping refers to the secondary aspects not directly associated with the loss itself. During this stage there is a reengagement back into life following the loss [21]. In this stage of the model, the individual is dealing with the secondary consequences of the loss, which leads to reflection and reorientation to oneself in the surrounding world without the deceased. This requires rethinking and re-planning of his or her life [22]. Oscillation between the two coping stages is a core feature of the DPM and can include having some avoidance or overlapping between each stage of coping [21].

In a longitudinal study of 219 couples conducted by Wijngaards de Meij, et al. [20] examined the relationship between parents and partners coping with a perinatal loss. This study concluded that loss orientation coping was more predictive of negative psychological adjustments after a loss. It was noted that higher levels of restoration orientation coping were related to increased levels of adjustment after a loss. Participants in this study were surveyed at six, thirteen, and twenty months post loss. High levels of restoration-oriented coping tended to minimize the effects of high levels of loss orientation associated with depression [20].

In a study conducted by Lund D, et al. [23], the DPM of coping was used to evaluate coping and knowledge in the bereaved widower population. It included a total sample of 298 recently widowed men over age 50. One hundred and twenty-eight men attended a 14-week traditional grief group that focused on loss orientation. One hundred seventy of the men attended a group that focused on both loss orientation and restoration orientation. This study found that the latter participants had higher levels of restoration-oriented coping, which is typically associated with better psychological adjustments after a loss. The researchers also 
reported a high degree of satisfaction with this program. Given the applicability of Lund and colleagues' study, a similar mode of grief work training was implemented in this pilot program

\section{Discussion}

\section{Literature synthesis critique}

A considerable body of literature about perinatal loss and the attributing factors exists; however, several gaps in the literature were noted. Though there are a variety of social support options available for families, consistent evaluation methods and instruments pertaining to grief and support are not frequently reported. Limited randomized clinical trials specific to perinatal loss were noted. The lack of information from randomized clinical trials suggest a need to determine if psychological support or counseling for mothers, fathers, and families after a perinatal loss is helpful or not [24]. This was also the case when assessing social support within other settings and populations. Specific to Flenady $\mathrm{V}$ and Wilson $\mathrm{T}$ [24] Cochrane review, most of the literature noted that social support was helpful, however, none of the reviewed randomized controlled studies evaluated social support. Also, similar to support literature in perinatal loss, small sample sizes with low statistical power were noted [24].

Limited literature was found specific to the integration of peer and professional support after a perinatal loss especially relating to the processes of coping, knowledge acquisition, quality of life, and satisfaction The promotion of knowledge does appear to be an effective way to enhance coping and promote wellness [12]. Therefore, interventions that facilitate coping through the grieving process while increasing knowledge may be helpful for persons experiencing perinatal loss. Implementing grief work group classes that promote knowledge acquisition specific to grief and coping, in conjunction with combined peer and professional support could potentially help families that have endured a perinatal loss.

The only Cochrane review regarding perinatal loss was ultimately unable to include any prior studies on review of this topic due to participant drop out [24]. This article also found that most of the prior studies looking at support and perinatal loss included small primarily female sample sizes [24]. These two findings were also noted in this pilot. These prior literature findings and this pilot's findings illustrate that further research is needed with this population with both males and females.

Overall, the literature did indicate that social support was helpful, which this pilot found also as mean scores for quality of life and satisfaction increased. Specifically, pilot qualitative analysis suggests that the integration of peer and professional support was helping in the grieving process [25-32].

\section{References}

1. Kiley G (2009) Leading mothers through their times of sorrow. Health Prog 90(4): 70-72.

2. Hutti MH, Armstrong DS, Myers J (2011) Healthcare utilization in the pregnancy following a perinatal loss. MCN Am J Matern Child Nurs 36(2): 104-111.
3. Hutti MH (2004) Social and professional support needs of families after perinatal loss. J Obstet Gynecol Neonatal Nurs 34(5): 630-638.

4. Murray JA, Terry DJ, Vance JC, Battistutta D, Connolly Y (2000) Effects of a program of intervention on parental distress following infant death. Death Stud 24(4): 275-305.

5. Lang A, Gottlieb LN, Amsel R (1996) Predictors of husbands' and wives' grief reactions following infant death: The role of marital intimacy. Death Stud 20(1): 33-57.

6. Barr P, Cacciatore J (2008) Personal fear of death and grief in bereaved mothers. Death Studies, 32(5), 445-460.

7. Mathew S, Cesario S, Symes L (2008) Explaining "unexplained" perinatal loss: Experiences of women with antiphospholipid syndrome. J Perinat Neonatal Nurs 22(4): 293-301.

8. Moules NJ, Simonson K, Fleiszer AR, Prins M, Rev Bob G (2007) The soul of sorrow work: Grief and therapeutic interventions with families. J Fam Nurs 13(1): 117-141.

9. Amoyal NR, Mason ST, Gould NF, Corry N, Mahfouz S, et al. (2011) Measuring coping behavior in patients with major burn injuries: A psychometric evaluation of the BCOPE. J Burn Care Res 32(3): 392-398.

10. Fisher MA, Mitchell GJ (1998) Patients' views of quality of life: Transforming the knowledge base of nursing. Clin Nurse Spec 12(3): 99-105.

11. Hibbard JH, Greene J (2013) What the evidence shows about patient activation: Better health outcomes and care experiences; fewer data on costs. Health Aff (Millwood) 32(2): 207-214.

12. Adams RJ (2010) Improving health outcomes with better patient understanding and education. Risk Manag Healthc Policy 3: 61-72.

13. Adams JM, Moreno J, Reynolds K, Campbell DW IV, Smith EO, et al. (1997) Resource utilization among neonatologists in a university children's hospital. Pediatrics 99(6): E2.

14. Wituk SA, Shepherd MD, Warren M, Meissen G (2002) Factors contributing to the survival of self-help groups. Am J Community Psychol $30(3): 349-366$.

15. Wilson AL, Soule DJ (1981) The role of a self-help group in working with parents of a stillborn baby. Death Educ 5(2): 175-186.

16. Hoey LM, Ieropoli SC, White VM, Jefford M (2008) Systematic review of peer-support programs for people with cancer. Patient Educ Couns $70(3): 315-337$.

17. Schopler JH, Galinsky MJ (1993) Support groups as open systems: A model for practice and research. Health Soc Work 18(3): 195-207.

18. Strebe M, Schut H (2010) The dual process model of coping with bereavement: a decade on. Omega (Westport) 61(4): 273-289.

19. Stroebe MS, Folkman S, Hansson RO, Schut H (2006) The prediction of bereavement outcome: Development of an integrative risk factor framework. Soc Sci Med 63(9): 2440-2451.

20. Wijngaards-de Meij L, Stroebe M, Schut H, Stroebe W, van den Bout J, et al. (2008) Parents grieving the loss of their child: Interdependence in coping. Br J Clin Psychol 47(Pt 1): 31-42.

21. Hooghe A, Neimeyer RA, Rober P (2012) "Cycling around an emotional core of sadness": Emotion regulation in a couple after the loss of a child. Qual Health Res 22(9): 1220-1231.

22. Richardson VE (2010) The dual process model of coping with bereavement: a decade later on. Omega (Westport) 61(4): 269-271.

23. Lund D, Caserta M, Utz R, De Vries B (2010) Experiences and early coping of bereaved spouses/partners in an intervention based on the dual process model (dpm). Omega (Westport) 61(4): 291-313.

24. Flenady V, Wilson T (2008) Support for mothers, fathers and families after perinatal death. Cochrane Database Syst Rev 1:CD000452.

25. Attkisson C (2012) Administering and scoring of the CSQ scales.

26. Attkisson C (2014) Client satisfaction questionnaire (CSQ-8). 
27. Burakhardt CS (2014) Instructions for scoring the quality of life scale.

28. Burckhardt CS, Anderson KL (2003) The quality of life scale (QOLS): Reliability, validity, and utilization. Health Qual Life Outcomes 1: 60-63.

29. Burckhardt CS, Anderson KL, Archenholtz B, Hagg O (2003) The Flanagan quality of life scale: Evidence of construct validity. Health Quality of Life Outcomes 1: 59.
30. McCreight BS (2004) A grief ignored: Narratives of pregnancy loss from a male perspective. Sociol Health Illn 26(3): 326-350.

31. O’Leary J, Thorwick C (2006) Fathers' perspectives during pregnancy, postperinatal loss. J Obstet Gynecol Neonatal Nurs 35(1): 78-86.

32. O’Leary J, Warland J, Parker L (2011) Bereaved parents' perception of the grandparents' reactions to perinatal loss and the pregnancy that follows. J Fam Nurs 17(3): 330-356. 